\title{
LA CAPSULE DES LEVURES
}

\author{
Par P. NEGRONI
}

En faisant l'étude analytique de l'antigène Mycotorula albicans, j'ai trouvé que, dans les milieux de culture liquides, apparaissaient des substances hydrocarbonées sécrétées par ce champignon. J'ai supposé alors que celles-ci pouvaient avoir leur origine dans la membrane cellulaire et être liées comme dans les bactéries à l'existence d'une capsule. En employant deş méthodes de coloration spéciales pour ce but, d'usage habituel en bactériologie, j'ai mis effectivement en évidence la présence d'une capsule dans les éléments cellulaires du champignon du muguet.

En étendant l'étude de la capsule à toutes les levures de la mycothèque de l'Institut bactériologique, j'ai pu déduire qu'un grand nombre de champignons levuriformes (et même non levuriformes), saprophytes ou parasites, présentent dans les milieux de cultures, spécialement dans ceux qui contiennent des hydrates de carbone, une capsule particulièrement visible au bout de 15 à 48 heures d'incubation à $37^{\circ} \mathrm{C}$. ou à la température du laboratoire.

L'existence d'une capsule dans les champignons levuriformes a été signalée quelquefois par erreur, en prenant pour elle un espace clair autour des cellules ou une membrane de double contour. C'est seulement dans certains cas (Cryptococcus hominis, Saccharomyces blanchardi, S. tumefaciens) qu'elle a été réellement individualisée, mais toujours dans le matériel procédant des lésions causées par des levures pathogènes.

Les méthodes de coloration essayées ont été l'encre de Chine, la méthode de Hiss et celle de Hunton (1932) (1) ; j'ai obtenu avec cette dernière les meilleurs résultats. Voici quel est ce procédé. On prépare la solution suivante :

Solution aqueuse d'acide phénique à 2 p. $100 \ldots \ldots \ldots, 100 \mathrm{~cm}^{3}$. Acide lactique concentré $\ldots \ldots \ldots \ldots \ldots \ldots \ldots \ldots, 0,25-0,50 \mathrm{~cm}^{3}$.

Acide acétique à 1 p. $100 \ldots \ldots \ldots \ldots \ldots \ldots \ldots \ldots, 1 \mathrm{~cm}^{3}$.

Solution alcoolique saturée de fuchsine basique ..... $1 \mathrm{~cm}^{3}$.

Fuchsine phéniquée vieille $\ldots \ldots \ldots \ldots \ldots \ldots \ldots \ldots, 1 \mathrm{~cm}^{3}$.

(1) Hunton. - Pure culture study of bacteria, I, 1932; $\mathrm{n}^{\circ} 2$.

Annales de Parastologie, T. XIV, ${ }^{\circ} 5 .-1^{\mathrm{er}}$ septembre 1936. 
On prépare séparément une solution de $3 \mathrm{gr}$. de nutrose (caséinate de soude) dans $100 \mathrm{~cm}^{3}$ d'eau distillée ; on la porte à l'autoclave sans pression à $100^{\circ} \mathrm{C}$., pendant une heure, puis on lui ajoute $5 \mathrm{~cm}^{3}$ d'une solution d'acide phénique à 2 p. 100. On la distribue dans des tubes à essais et on l'emploie après décantation.

Sur l'extrémité d'une lame, on met une goutte de cette solution de nutrose en émulsionnant avec elle une parcelle de la culture de la levure avec une anse. Avec une lame, coupée selon la technique décrite par Wright dans son travail sur les opsonines, on étend alors le matériel comme pour faire un frottis de sang et on l'agite pour le sécher rapidement à l'air. Ensuite on verse (sans fixation préalable) le colorant en le laissant agir trente secondes. On lave, on laisse sécher et on examine.

L'emploi de cette méthode de coloration permet la division des levures en trois groupes : 1 , celles qui forment une capsule ; 2 , celles qui produisent une substance intercellulaire et 3, celles qui semblent ne produire ni capsule ni substance intercellulaire.

\section{$1^{\mathrm{er}}$ GROUPE : Levures qui forment une capsule}

Cultures dans le moût de bière liquide, $p \mathrm{H} 6,5,48 \mathrm{~h}$. à $25^{\circ} \mathrm{C}$.

Nom et provenance des cultures

Atelosaccharomyces hudeloi (Cryptococus hominis) (Prof. da Fonseca, Rio de Janeiro).

Blastodendrion erectum $\left(\mathrm{D}^{\mathrm{r}}\right.$ Mackinnon, Montevideo).

Blastodendrion intermedium $\left(\mathrm{D}^{\mathrm{r}}\right.$ Mackinnon, Montevideo).

Candida sp. (D ${ }^{r}$ Mackinnon, Montevideo).

Cryptococcus castellanii (Prof. Castellani, Londres).

Cryptococcus hominis (Prof. Vuillemin, France).

Cryptococcus ludwigi (Prof. Guilliermond, Paris).

Endomyces chodati (Prof. Guilliermond, Paris).

E. fibuliger (Prof. Guilliermond, Paris).
ObSERVATIONS

Capsule à bords flous, grand espace clair péricellulaire.

Capsule particulièrement visible dans les cellules allongées.

Capsule à bords flous, grand espace clair péricellulaire.

Capsule épaisse à bords effrangés. 
Cultures dans le moût de bière liquide, $p \mathrm{H} 6,5,24$ h. à $30^{\circ}$

Endomyces magnusi (Prof. Guill., Paris).

E. margaritæ (Prof. Guill., Paris).

E. trumpfii (Prof. Guill., Paris).

Geotrichoides krusei ( $\mathrm{D}_{1}^{r}$ Mackinnon, Montevideo).

Guilliermondella selenospora $\left(\mathrm{P}^{\mathrm{r}}\right.$ Guilliermond, Paris).

Levure «bili longue » (Prof. Guilliermond, Paris).

Levure «bili ronde» (Prof. Guilliermond, Paris).

Levure «de Colombie» (Prof. Guilliermond, Paris).

Levure « Franquet 》 (Prof. Guilliermond, Paris).

Levure " gingembre ronde». $\left(\mathrm{P}^{\mathrm{r}}\right.$ Guilliermond, Paris).

Levure « $\mathrm{K}$ 》 (Professeur Guilliermond, Paris).

Levure «maleçon » (Prof. Guilliermond, Paris).

Levure « $\mathrm{Ob}$ » (Professeur Guilliermond, Paris).
Capsule à limites diffuses.

Capsule épaisse.

Capsule mince.

Capsule épaisse.

Id.

Capsule épaisse, espace clair péricellulaire large.

Id.

Capsule mince en forme d'anneau.

Id.

Cultures sur agar glucosé, 36 h. à $20^{\circ}-25^{\circ}$ C.

Levure «Pp» (Prof. Guilliermond, Paris).

Levure «de sécrétion» (Prof. Guilliermond, Paris).

Levure de fermentation de mélasse, race III $\left(D^{r}\right.$ Gomes de Faria, Rio de Janeiro).

Levure de fermentation de mélasse, race II $\left(\mathrm{D}^{\mathrm{r}}\right.$ Gomes de Faria, Rio de Janeiro).
Capsule mince en forme d'anneau. 
Cultures sur moût de bière gélosé, $p H 7,24$ h. à $20^{\circ}-25^{\circ}$

Levure de vin Bordeaux (D ${ }^{r}$ G. de F., R. de J.).

Mortilia Brocq-Rousseu (Prof. Guil., Paris).

Monilia butantanensis (Prof. Fons., R. de J.).

Monilia macedoniensis (Prof. Cast., Londres).

Monilia pinoyi (Prof. Cast., Londres).

Monilia psilosis (Prof. Fonseca, R. de Jan.).

Monilia tropicalis (Prof. Fonseca, R. de Jan.).

Mycoderma cerevisiæ (D ${ }^{\mathrm{r}}$ Soriano, B.-Ayres).

Pichia farinosa (D ${ }^{\mathrm{r}}$ Soriano, Buenos-Ayres).

Nematospora phaseoli (Prof. Guilliermond, Paris).
Capsule à bords déchiquetés.

Capsule ample sans limites nettes.

Cultures sur agar glucosé, 24 h. à $20^{\circ}-25^{\circ} \mathrm{C}$.

Saccharomyces cerevisiæ $\left(\mathrm{D}^{\mathrm{r}} \mathrm{Ne}-\right.$ groni, B.-Ayres).

Saccharomyces chevalieri (Prof. Guil., Paris).

Saccharomyces lactis (Prof. Guil., Paris).

Saccharomyces «Pathogène Binot 》 (Prof. Guil., Paris).

Saccharomyces müntzii (Prof. Guil., Paris).
Capsule mince en forme d'anneau.

Cultures sur agar glucosé, 3 jours à $20^{\circ}-25^{\circ} \mathrm{C}$.

Saccharomyces paradoxus (Prof. Capsule à bords flous. Guil., Paris).

Sporobolomyces salmonicolor $\left(\mathrm{P}^{\mathrm{r}}\right.$ Guil., Paris). 
Torula Morr. 11345 (Prof. Fonseca,

Capsule mince en forme d'anneau.

Rio de Janeiro).

Cultures sur moût de bière gélosé, 24 h. à $30^{\circ} \mathrm{C}$.

Schizosaccharomyces pombe (Prof. Guill., Paris).

Willia anomala $\left(\mathrm{D}^{\mathrm{r}}\right.$ Negroni, Buenos-Ayres).

Cultures en bouillon glucosé, 3 jours à $30^{\circ} \mathrm{C}$.

Saccharomyces annulatus $\left(\mathrm{D}^{\mathrm{r}}\right.$ Ne- Capsule à bords un peu flous. groni, Buenos-Ayres).

Torula histolytica (D ${ }^{\text {rs }}$ Rappoport

et Kaplan, Chicago).

$2^{\text {me }}$ GROUPE : Levures qui forment une substance intercellulaire

Cultures en moût de bière, $p \mathrm{H} 6,5,24 \mathrm{~h}$. à $30^{\circ} \mathrm{C}$.

Endomyces lindneri (Prof. Guill., Paris).

Levure « écorce d'orange 》 (Prof. Guill., Paris).

Levure « $\mathrm{Fb} »$ (Prof. Guill., $\mathrm{Pa}$ ris).

Levure « $G »$ (Prof. Guill., Paris). Levure « gingembre longue 》 $\left(\mathrm{P}^{\mathrm{r}}\right.$ Guill., Paris).

Levure «Péju 27 » (Prof. Guill., Paris).

Levure «Péju 271 » (Prof. Guill., Paris).

Levure «Pf» (Prof. Guill., Paris).
Substance intercellulaire rouge foncé, parfois des capsules en forme d'anneau. 
Cultures sur agar glucosé, 36 h. à la temp. du labor.

Levure «Pv» (Prof. Guilliermond, Paris).

Levure «V 》 (Prof. Guilliermond, Paris).

Levure «Vincens 852 » (Prof.

Guilliermond, Paris).

Levure de mélasse, race $I, n^{0} 4$ $\left(D^{r}\right.$ Gomes de Faria, Rio de Janeiro).

Levure pressée (Danemark) (D Gomes de Faria, Rio de Janeiro).

Cultures sur moût de bière gélosé, $p H 7,24$ h. à la temp. du labor.

Levure de mélasse, race I ( $\mathrm{D}^{\mathrm{r}}$ Gomes de Faria, Rio de Janeiro).

Levure de mélasse $\left(\mathrm{D}^{\mathrm{r}}\right.$ Gomes de Faria, Rio de Janeiro).

Monilia parapsilosis (Prof. Fonseca, Rio de Janeiro).

Cultures sur agar glucosé, 3 jours à la temp. du laboratoire

Monilia pseudotropicalis (Prof.

Cast., Londres).

Torula cremoris ( $\mathrm{D}^{\mathrm{r}}$ Soriano, Buenos-Ayres).

Zygosaccharomyces pastori (Prof. Guilliermond, Paris).

$3^{\text {mo }}$ GROUPE : Levures qui semblent ne produire ni capsule ni substance intercellulaire

Cultures en moût de bière, $p H 6,5,48$ h. à la temp. du labor. Cryptococcus agregatus (Prof. da Fonseca, Rio de Janeiro. 
Cryptococcus mena (Prof. da Fonseca, Rio de Janeiro).

Debaryomyces globosus (Prof. Guill., Paris).

Debaryomyces matruchoti (Prof. Guill., Paris).

Debaryomyces tyrocola (Prof. Guill., Paris.

Endomyces javanensis (Prof. Guill., Paris).

Cultures en moût de bière, $\mathrm{p} H 6,5,24$ heures à $30^{\circ} \mathrm{C}$.

\section{Endomyces mali.}

Geotrichum pulmoneum ( $\mathrm{D}^{\mathrm{r}}$ Mackinnon, Montevideo).

Levure « $\mathrm{Bl} »$ (Prof. Guill., Paris).

Levure « $\mathrm{Bm} »$ (Prof. Guill., Paris).

Levure «Gancea 》 (Prof. Guill., Paris).

Levure « Cesari, B » (Prof. Guill., Paris).

Levure « du cédrat » (Prof. Guill., Paris).

Levure «Fm » (Prof. Guill., Paris).

Levure « $\mathrm{H} \gg$ (Prof, Guill., $\mathrm{Pa}$ ris).
Un peu de substance intercellulaire dans les angles dièdres.

Capsule en forme d'anneau autour de quelques cellules.

Id.

Cultures sur agar glucosé, 36 heures à la tempér. du labor.

Levure «Péju 852 » (Prof. Guill., Paris).

Levire «de rose » (Prof. Guill., Paris). 
Cultures sur moût bière gélosé, $p H$ 7, 24 h. à la temp. du labor.

Levure « Sb» (Prof. Guill., Paris).

Mycocandida sp. (D ${ }^{\mathrm{r}}$ Mackinnon, Montevideo).

Mycotoruloüdes sp. (D ${ }^{\mathrm{r}}$ Mackinnon, Montevideo).

Cultures en bouillon glucosé, 24 h. à la temp. du labor.

Saccharomyces ellipsö̈deus (Prof. Guill., Paris).

Schizosaccharomyces mellacei (Prof. Guill., Paris).

Cultures en bouillon glucosé, 3 jours à la temp. du labor.

Schizosaccharomyces hom in is

(Prof. Benedek, Leipzig).

Torula colliculosa (Prof. Guill., Paris).

Torula Moor. 1076 (Prof. Fonseca, Rio de Janeiro).

Zygosaccharomyces mali (Prof.

Guill., Paris).

Zygosaccharomyces mandshuricus (Prof. Guill., Paris).

Zygosaccharomyces p r i o r i a n $\mathrm{s}$

(Prof. Guill., Paris).

Les champignons sont désignés ici avec les noms qu'ils portaient au moment où ils ont été reçus.

\section{Aspects des préparations colorées par la méthode de Hunton}

Les cellules vivantes apparaissent uniformément teintes en rouge, les cellules vieilles ou mortes se colorent irrégulièrement et présentent dans leur intérieur des corpuscules métachromatiques rouge-violacés. 
La capsule a l'aspect d'une fine pellicule rose qui entoure les cellules; il existe toujours un espace clair entre celles-ci et la capsule.

La largeur de cet espace clair péricellulaire et de la capsule, ainsi que son homogénéité et ses bords sont à tel point variables qu'on peut dire que chaque espèce a sa manière particulière de former sa capsule. Cependant, il y a des groupes de levures dont la capsule présente des bords nets : Mycotorula albicans, Candida sp., Endomyces fibuliger, margaritae, trumpfii, etc. D'autres dont la capsule présente des limites diffuses : Cryptococcus hominis, ludwigi, Endomyces magnusi, etc. Finalement, il existe des levures qui ont une capsule tellement mince qu'elle se réduit à un anneau fortement coloré, ex. : Endomyces lindneri, Saccharomyces chevalieri, Schizosaccharomyces pombe, etc.

Dans le groupe de levures qui forment une substance intercellulaire, il y a aussi des variantes dans la quantité et l'intensité de la coloration de cette dernière.

Dans le $3^{\text {e }}$ groupe, il y a des levures ne formant pas de substance intercellulaire et d'autres qui la produisent en très petite quantité. Dans ce cas, elle s'accumule dans les angles dièdres que forment entre elles les cellules par pression réciproque ou les cellules mères avec leurs bourgeons et se présente comme fortement colorée.

Nature de la capsule. - La substance intercellulaire est probablement de la même nature que celle de la capsule; on l'extrait également avec une solution de soude à 1 p. 100 à chaud et elle précipite par l'alcool-acétate de soude à 13 p. 100. Les solutions aqueuses donnent la réaction de Molisch positive, ne réduisent pas la liqueur de Fehling, mais elles la réduisent hydrolysée par les acides à chaud ( 15 à 30 minutes d'ébullition). Il s'agit probablement d'un polysaccharide facilement soluble dans l'eau, appelé aussi substance spécifique soluble ou matière gommeuse des levures, sécrété par la membrane et appartenant au groupe des formations métaplasmatiques. Si les observations de Müller et Tomesik sur les levures pressées et celles de l'auteur sur la Mycotorula albicans se trouvent confirmées pour les autres levures, ce polysaccharide manque de propriétés immunisantes « in vivo », mais se comporte comme un antigène précipitant et fixateur du complément « in vitro », vis-à-vis du sérum des animaux immunisés avec la levure totale, c'est donc un haptène dans le sens de Landsteiner. Ces solutions aqueuses ne donnent pas la réaction de biuret ni d'autres réactions des protéines, mais elles contiennent une quantité d'azote variant de 0,50 à 1 p. 100. 
Elles donnent comme produit d'hydrolyse du glycose décelable par la réaction du glycosazone.

Ce polysaccharide se répand dans les milieux liquides de culture d'où on peut l'extraire par précipitation par l'alcool-acétate de soude.

La capsule des levures s'observe mieux dans les cultures jeunes de 15 heures, pour celles dont la température optima de développement est de $37^{\circ}$; de 24 à 48 heures, pour celles qui se développent mieux à la température du laboratoire; c'est-à-dire, dans les deux cas, quand, à la surface des milieux de culture solide, commence à paraître un vernis ou pellicule.

Quand on étudie des cultures en milieux liquides, il est bon de laver (par centrifugation) le sédiment une ou deux fois dans l'eau, avant de faire les préparations, car la substance de la capsule diffusée dans le milieu de culture se colore en rose et rend difficile l'obtention de bonnes préparations.

Il est très probable qu'en changeant les conditions d'expérience, on arrive à observer de vraies capsules dans des levures du $2^{\mathrm{e}}$ ou du $3^{\circ}$ groupe. C'est ce qui s'est passé avec le Saccharomyces annulatus et la Torula histolytica, en étudiant des cultures très jeunes dans du bouillon glycosé.

Finalement, j'ai essayé, sans y parvenir, une double coloration de la capsule et du corps de la cellule.

Institut bactériologique du Département national d'hygiène, Buenos-Aires (Directeur : Prof. A. Sordelli).

\section{EXPLICATION DE LA PLANCHE XXIII}

Fig. 1. - Capsule du Cryptococcus hominis. Culture en moût bière, 48 h. à $25^{\circ}$.

Fıg. 2. - Substance intercellulaire dans les angles dièdres du Geotrichum pulmoneum.

Fig. 3. - 1. Capsule de la levure «Franquet ». Culture en moût de bière, 24 h. à $30^{\circ} ; 2$. Capsule de l'Endomyces trumpfii.

Fig. 4. - - 1. Capsule à bords flous du Saccharomyces annulatus. Culture en bouillon glucosé ; 2. Capsule de Torula histolytica.

Fig. 5. - Capsule du Mycotorula albicans. Culture sur agar-glucosé de 15 heures à $37^{\circ} ; 1$, capsule d'aspect normal ; 2 , décomposition en feuillets stratifiés, détachement du corps de la cellule et éclatement de la capsule à la suite des lavages répétés ; 3 , substance intercellulaire, teinte en rouge foncé. 

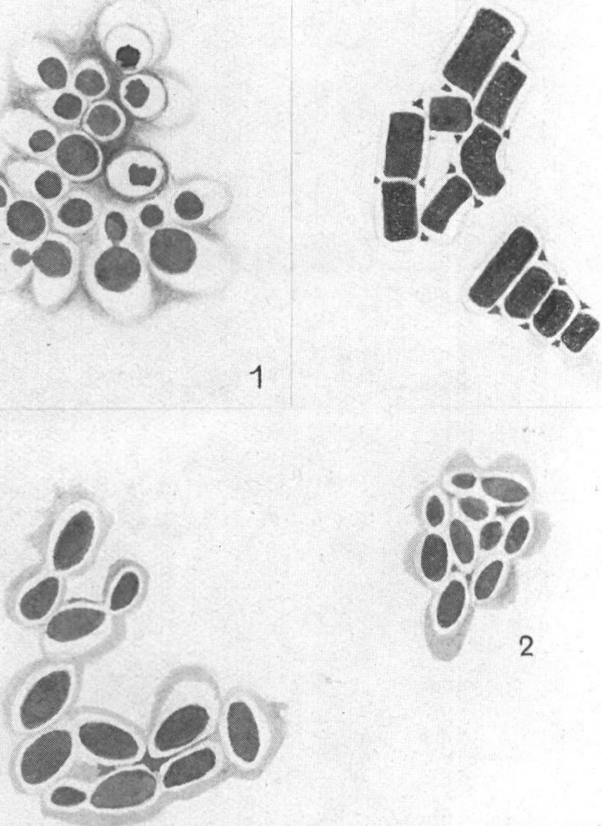

2

1

3
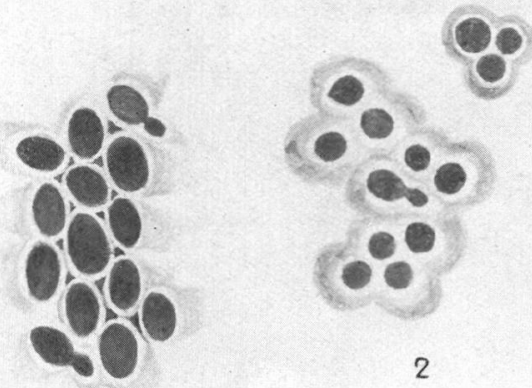

2

1

4

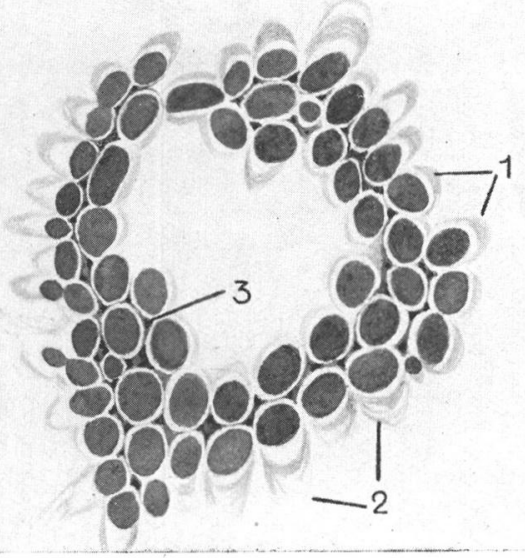

